\title{
From Bench to Bedside: Report of the Sixth International Stroke Summit, Nanjing, China, July 9-11, 2010
}

\author{
Yongjun Jiang Gelin Xu Xinfeng Liu \\ Department of Neurology, Jinling Hospital, Nanjing University School of Medicine, Nanjing, China
}

Stroke is a leading cause of death and long-term disability worldwide [1]. It is estimated that about half of the stroke patients live in Asia and one fourth in China [1]. During the past decades, researchers have made significant progress in stroke mechanisms and clinical management. The International Stroke Summit is one of the regular activities endorsed by the World Stroke Organization to deliver new concepts of prevention and treatment of cerebrovascular diseases in China and other Far East countries. This annual conference has successfully convened 6 times since 2004 .

The Sixth International Stroke Summit was held in Nanjing on July 9-11, 2010. Encouraging translational study is the main topic of this year's summit. The summit was cochaired by Dr. Xinfeng Liu from Jinling Hospital, Nanjing University School of Medicine, China, and Dr. Yangtai Guan from Changhai Hospital, Shanghai, China. Dr. Liu made an opening address on behalf of the organizers, in which he emphasized that the motif of the summit is to build a platform for communications between east and west and translate the latest research results to bedside treatment.

Dr. Xinfeng Liu also gave a lecture on the role of endovascular therapy in the treatment of cerebrovascular diseases and introduced recent progress in endovascular techniques. He introduced the Carotid Revascularization Endarterectomy versus Stenting Trial [2], which was the largest prospective randomized trial to date comparing carotid artery stenting and carotid endarterectomy. In the Carotid Revascularization Endarterectomy versus Stenting Trial, carotid artery stenting was associated with a $7.2 \%$ rate of primary events versus $6.8 \%$ with carotid endarterectomy, a nonsignificant difference. Although debates still exit concerning the priority of stenting versus surgery for carotid disease, Dr. Liu pointed out that due to a shortage of skilled neurosurgeons and the reluctance of patients to undergo a major operation in the neck, carotid artery stenting was more acceptable in China. Dr. Liu also mentioned the technical advances in the endovascular solutions.

Dr. Yukito Shinohara from Tachikawa Hospital in Tokyo, Japan, is the principal investigator of the Cilostazol Stroke Prevention Study (CSPS). He delivered a lecture on the clinical trial for stroke prevention (CSPSII). CSPSII is a randomized, multicenter, double-blind, parallel-group study, including 2,757 noncardio- embolic stroke patients from 278 centers. The patients were randomized to a cilostazol group (1,337 patients) and an aspirin group (1,335 patients). The duration of follow-up ranged from 1 to 5 years. Eighty-two stokes occurred in the cilostazol group, and 2 of these events were fatal. There were 119 strokes, including 3 deaths in the cilostazol group. Hemorrhagic stroke or internal hemorrhage requiring hospitalization was observed in 23 patients in the cilostazol group and 57 in the aspirin group. Dr. Shinohara pointed out that cilostazol would be an alternative choice in our arsenal against secondary stroke besides aspirin and clopidogrel.

Dr. Jinsheng Zeng introduced the Chinese Ischemic Stroke Guideline (2010). The guideline emphasizes the importance of control of stroke risks. When Dr. Zeng talked about the treatment of ischemic stroke, he pointed out that the guideline was based on the research data accumulated up to July 2008. Since then, quite a few trials have been published such as the European Cooperative Acute Stroke study III.

About 1,200 doctors and physicians from China and overseas participated in the summit. In the closing ceremony, the organizers announced that the Seventh International Stroke Summit will be held in Nanjing, China, in July 2011. Thirty selected abstracts submitted to the conference were published in Cerebrovascular Disease [3]. Detailed information concerning the conference is available on the website: www.stroke.net.cn.

\section{References}

1 Liu M, Wu B, Wang WZ, Lee LM, Zhang SH, Kong LZ: Stroke in China: epidemiology, prevention, and management strategies. Lancet Neurol 2007;6:456-464.

-2 Brott TG, Hobson RW 2nd, Howard G, Roubin GS, Clark WM, Brooks W, Mackey A, Hill MD, Leimgruber PP, Sheffet AJ, Howard VJ, Moore WS, Voeks JH, Hopkins LN, Cutlip DE, Cohen DJ, Popma JJ, Ferguson RD, Cohen SN, Blackshear JL, Silver FL, Mohr JP, Lal BK, Meschia JF: Stenting versus endarterectomy for treatment of carotid-artery stenosis. N Engl J Med 2010;363:11-23.

-3 Selected abstracts for the Sixth international stroke summit. Cerebrovasc $D$ is 2010;30:207-219.

\section{KARGER}

Fax +41613061234 E-Mail karger@karger.ch www.karger.com
(C) 2010 S. Karger AG, Base

$1015-9770 / 10 / 0305-0535 \$ 26.00 / 0$

Accessible online at:

www.karger.com/ced
Xinfeng Liu

Department of Neurology, Jinling Hospital, Nanjing University School of Medicine 305 Zhongshan East Road

Nanjing 21002 (China)

Tel. +86 258527 2631, Fax +86 258480 1861, E-Mail xfliu2@yahoo.com.cn 